\title{
A PERCEPÇÃO CLIMÁTICA DA OCORRÊNCIA DE ESTIAGENS E OS PROBLEMAS DE ABASTECIMENTO DE ÁGUA NA ÁREA URBANA DO MUNICÍPIO DE BAGÉ -
}

RS

\author{
Ana Rosa Pacheco Brondani ${ }^{1}$ \\ Cássio Arthur Wollmann ${ }^{2}$ \\ Arnaldo de Araújo Ribeiro ${ }^{3}$
}

Resumo: As estiagens fazem parte do cotidiano da população sul-rio-grandense, as quais afetam o desenvolvimento regional. Nesta pesquisa, avaliou-se quantitativamente a percepção ambiental dos moradores urbanos de Bagé, RS, sobre a ocorrência de estiagens e seus impactos relacionados ao uso da água. O estudo baseou-se na metodologia utilizada por Wollmann; Sartori (2010) e Ribeiro (2012), que consiste na aplicação de questionário de perguntas abertas e fechadas para a população de áreas atingidas por extremos climáticos. Observou-se que a população percebe a ocorrência de estiagem há pelos menos 25 anos, $e$ tal situação climática leva à ocorrência de falta de água, no verão em Bagé, há pelo menos duas décadas, bem como se observou o descaso com o uso da água.

Palavras-chave: percepção climática, estiagens, abastecimento de água, Bagé, RS.

\section{Climatic Perception of Occurrence of Droughts and Water Supply Problems in Urban Area of The City of Bagé - RS}

\begin{abstract}
Droughts are part of everyday life of the population south of Rio Grande do Sul which affect regional development. This research concerns in evaluate quantitatively the environmental perception of urban residents Bagé, $R S$, on the occurrence of drought and its impacts related to water use. The study was based on the methodology used by Wollmann, Sartori (2010) and Ribeiro (2012), which consists of a questionnaire of open and closed questions for the population of areas hit by weather extremes. It was observed that people perceive the occurrence of drought there are at least 25 years, such a climate situation leads to the occurrence of lack of water in summer Bagé, there are at least two decades and was observed using the disregard of water.
\end{abstract}

Key-Words: Climatic perception, droughts, water supply, Bagé, RS.

\section{INTRODUÇÃO}

Uma estiagem, tratada vulgarmente como seca, é entendida como um fenômeno atmosférico de origem natural com propriedades bem características e distintas das demais, em outras palavras, é entendida como uma condição física transitória, caracterizada pela escassez de água, associada a períodos extremos de reduzida precipitação mais ou menos

\footnotetext{
${ }^{1}$ Secretaria da Educação do Estado do Rio Grande do Sul, Professora de Geografia, Rosário do Sul - RS. E-mail: arosabrondani@gmail.com ${ }^{2}$ Geógrafo, doutor em Geografia Física pela Universidade de São Paulo. Professor Doutor da Universidade Federal de Santa Maria, Centro de Ciências Naturais e Exatas, Departamento de Geociências, Curso de Geografia. Email: cassio_geo@yahoo.com.br

${ }^{3}$ Mestre em Geografia - Universidade Estadual Paulista "Júlio de Mesquita Filho" Instituto de Geociências e Ciências Exatas, UNESP - Rio Claro, SP. E-mail: ribeirogeo@yahoo.com.br DOI: 10.7154/RDG.2013.0026.0011
} 
longos, com repercussões negativas e significativas nos ecossistemas e nas atividades socioeconômicas (SILVEIRA, et. al., 2006).

Existe diferença conceitual entre seca e estiagem abordada em inúmeros autores, aos quais, Conti (2008) faz referência à abordagem dada por Colville (1987) que trata a seca recíproca de uma região quando a precipitação anual for inferior a $60 \%$ da normal, durante mais de dois anos consecutivos, em mais de $50 \%$ de sua superfície. Pressupõe, ainda, que os ecossistemas e os sistemas econômicos podem resistir a uma diminuição da precipitação em $40 \%$, durante um ano, mas serão afetados, seriamente, quando o fenômeno se repetir durante dois anos em sequência.

Estiagem é o fenômeno que ocorre num determinado intervalo de tempo, ou seja, a estiagem não é permanente e às vezes não tão severa quanto à seca do ponto de vista do ressecamento da atmosfera e do solo, contrariamente à seca, que é por vezes mais severa e de caráter permanente (CARVALHO, 1988).

No Rio Grande do Sul, as estiagens deixam marcas lastimáveis na agricultura gaúcha durante o verão, pois conforme Silveira, et. al. (op. cit., p. 2), as estiagens no Estado:

... são uma condição climática, determinadas pelos fenômenos El Niño e La Niña, que atuam predominantemente no período da primavera e do verão. Embora as chuvas no Rio grande do Sul sejam bem distribuídas durante as quatro estações do ano, a precipitação pluvial no estado caracteriza-se pela elevada variabilidade interanual (entre anos) e espacial (entre regiões), o que contribui para acentuar a estiagem em determinadas regiões.

Nesse sentido, historicamente as estiagens fazem parte do cotidiano da população de várias cidades sul-rio-grandense, e a frequência de ocorrência desse fenômeno climático é alta (RIBEIRO, 2012).

No caso da pesquisa aqui apresentada, que tem o município de Bagé como espaço de análise, o mesmo tem sofrido com sucessivas estiagens que afetam, principalmente, o desenvolvimento da região (GOMES, 2012).

Bagé e seu entorno tem passado por períodos de longas estiagens e secas principalmente nas últimas 4-5 décadas, as quais estão relacionadas com os períodos de atuação do fenômeno La Niña. Esses períodos de estiagem afetam de modo mais veemente, o abastecimento público de água potável da população que vive nas sedes municipais e em distritos da zona rural do município. Nesses períodos, o município tem decretado sucessivos racionamentos e estados de emergência (GOMES, 2012). 
Segundo o Plano Diretor Municipal, a estrutura de abastecimento de água de Bagé é formada por três barragens: Sanga Rasa, Piraysinho e Emergencial. A Barragem Sanga Rasa é a maior reserva, porém, devido à ausência de vertentes, apresenta dificuldades de recuperação do nível de água. Há, ainda, a Barragem Rio Negro, que mesmo estando próxima da área urbana, é utilizada para irrigação na zona rural (Figura 01).

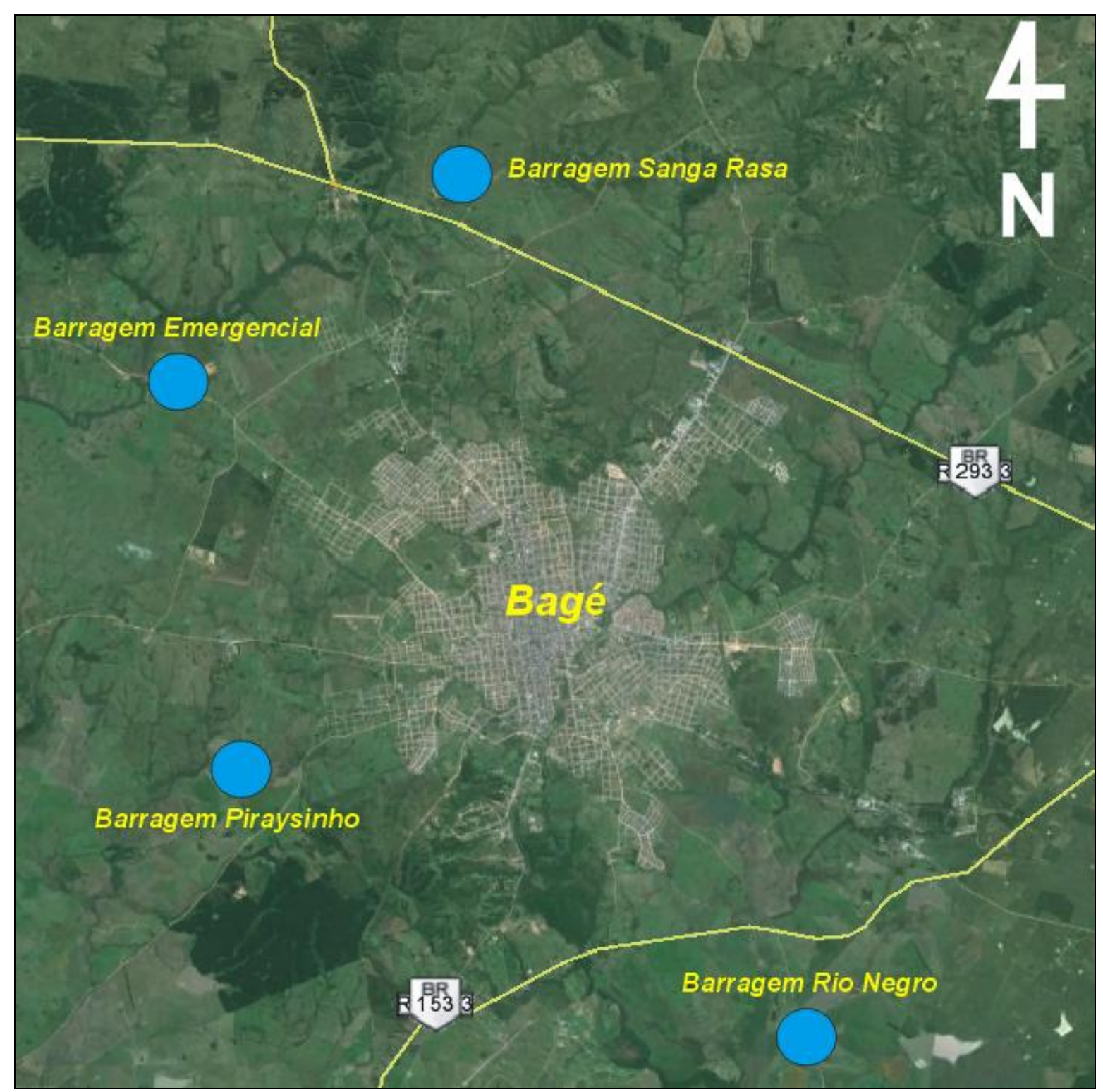

Figura 01: Mapa de localização das barragens de abastecimento urbano de Bagé - RS. Fonte: Google Earth, 2013. Elaborado pelo autor.

A Barragem do Piraysinho apresenta maior estabilidade, sendo provida de boas vertentes, mas sua capacidade não é grande. Já a Barragem Emergencial, criada a partir de um barramento no Arroio Piraysinho, contribui com $1 / 3$ da água do abastecimento da cidade e sua captação é relativa à vazão do Arroio. Atualmente, está em andamento a construção da Barragem da Arvorezinha (GOMES, 2012), que é uma ampliação da Barragem Emergencial. 
Surge, assim, a necessidade de se entender e divulgar as questões relacionadas as estiagens no estado do Rio grande do Sul, sendo relevante a análise do fenômeno e sua repercussão em primeiro momento a partir da percepção ambiental por parte dos habitantes dos locais diretamente afetados por estiagens. Conforme Pascoalino (2009) "os homens percebem individualmente o ambiente que os circunda, porém, as percepções individuais diferenciamse de acordo com a sensibilidade e o interesse individual sobre os objetos que são apreendidos de forma seletiva."

Assim, para Ribeiro (2012) "dentre os objetos apreendidos de forma seletiva, o tempo atmosférico e o clima tem grande influência na percepção que se faz do convívio do homem com o meio ambiente no dia-a-dia". Em razão disso os fatos e consequências advindos do clima também são bastante observados pelo homem.

Desta forma a "percepção do meio ambiente" preconizada por Oliveira $(1971 ; 1977)$ e trabalhada por Sartori (2000), Oliveira (2005), Ruoso (2007), Pascoalino (2009), Wollmann; Sartori (2010) e Ribeiro (2012) servem como norteadores para esta primeira abordagem de percepção das estiagens em Bagé.

Sendo esta uma primeira abordagem a respeito das estiagens e da percepção ambiental das mesmas pela população urbana de Bagé, convencionou-se avaliar quantitativamente, como objetivo principal, a percepção ambiental e climática dos moradores da área urbana de Bagé, RS, sobre a ocorrência de eventos de estiagens e seus impactos relacionados ao uso da água.

Os demais objetivos da pesquisa, foram possíveis através da aplicação de questionários de investigação da percepção ambiental dos moradores da cidade sobre a ocorrência de eventos de estiagens; além da realização um levantamento do conhecimento que a população tem sobre os principais motivos que levam à falta de água no município em épocas de estiagem.

Realizou-se, ainda, um apanhado teórico, de forma a explicar em que se consiste o estudo de percepção do meio ambiente, bem como se mostrou de forma geral os aspectos climáticos referentes às chuvas no estado do Rio Grande do Sul.

Também como objetivo, buscou-se verificar se a população possui conhecimento sobre a execução de projetos que minimizem a problemática da falta de água em Bagé em situações de estiagem e em que ela contribui para o racionamento de água; e levantaram-se possíveis propostas de incentivo à redução do consumo de água em épocas de estiagem. 


\section{Localização e Caracterização Climática da Área de Estudo}

Bagé é um município brasileiro do estado do Rio Grande do Sul localizado em zona de fronteira com a República do Uruguai, conforme mostra o mapa da Figura 02. Pertence à Mesorregião do Sudoeste Rio-grandense e à Microrregião da Campanha Meridional, localizando-se próximo ao rio Camaquã. A altitude média da cidade é de 212 metros acima do nível do mar, incluindo-se na área de dominio do Bioma Pampa Meridinal, ou no Pampa Gaúcho.

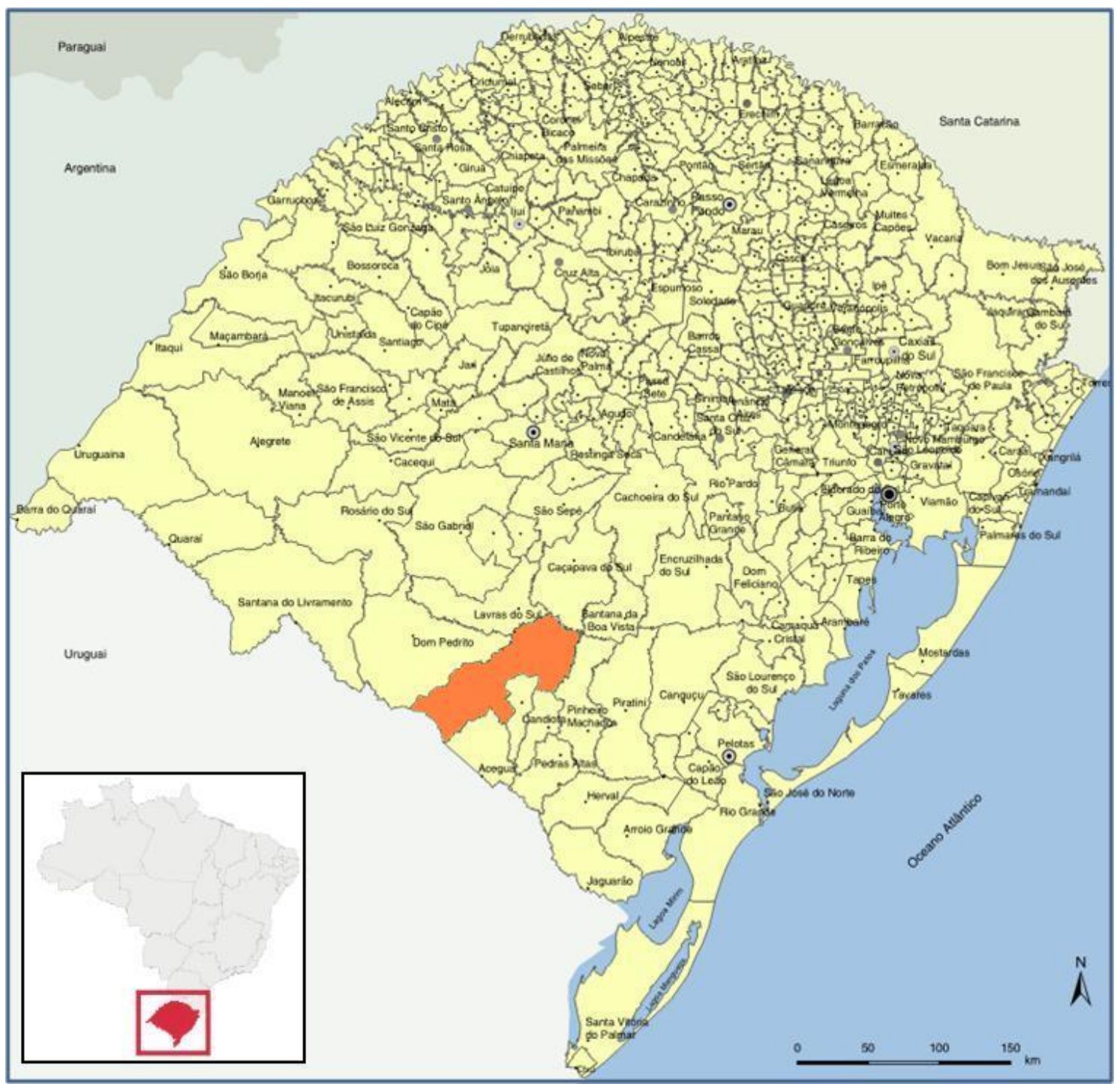

Figura 02: Mapa de localização do município de Bagé no Rio Grande do Sul. Fonte:Atlas Socioeconômico do Rio Grande do Sul (SEPLAG-RS, 2006). Adaptado pelo autor. 
O Pampa é o berço do povo gaúcho, cuja cultura e tradições foram construídas sobre os nativos de um território de fronteira flutuante e em íntima associação com a atividade econômica, inicialmente desenvolvida na região que era a criação extensiva de gado.

É impossível pensar no Pampa sem que imediatamente venha à mente a figura do gaúcho, o habitante natural da região completamente integrado ao seu meio e hoje conhecido muito além das fronteiras do Rio Grande do Sul (CHOMENKO, 2008).

A região de Bagé serviu de palco para diversos conflitos entre europeus e nativos. Destacase o ocorrido em 1752, quando 600 índios charruas, comandados por Sepé Tiaraju, rechaçaram os enviados das coroas de Portugal e Espanha que, amparados no tratado de Madri, assinado dois anos antes, regulamentando os limites territoriais dos dois impérios na América do Sul, vieram para estabelecer as fronteiras (CHOMENKO, 2008).

Quanto aos aspectos atuais, demográficos, em 2010, segundo o Censo do Instituto Brasileiro de Geografia e Estatística (IBGE), o município de Bagé possui 116.794 habitantes e uma densidade demográfica de 28,52 hab. $/ \mathrm{km}^{2}$ em 2008 , sendo que a população urbana é de 97.765 habitantes e a população rural em 2010 atinge a marca de 19.029 habitantes, assim sendo, $84 \%$ e $16 \%$, respectivamente, da população bageense habita a zona urbana e rural do município (IBGE, 2010).

Nesse sentido, as estiagens são muito percebidas pela população urbana justamente pelo fato de que a maioria da população vive na cidade, e que depende quase que exclusivamente do abastecimento público. Assim, justifica-se a aplicação dos questionários apenas na área urbana, ainda que a priori.

Em 2000 a expectativa de vida ao nascer era de 70,68 anos e o coeficiente de mortalidade infantil era de 7,78 em 2008. O IDH de Bagé, em 2010, era de 0,895. Segundo a classificação do Programa das Nações Unidas para o Desenvolvimento (PNUD), o município está entre as regiões consideradas de alto desenvolvimento humano (IBGE, 2010).

Quanto às características climáticas o Rio Grande do Sul apresenta-se, quanto à denominação climática baseada em Köppen algumas divergências, segundo Moreno (1961). Conforme o autor alguns denominam o clima do Estado como Subtropical, e outros como Temperado e, ainda, como Subtropical e Temperado. A imprecisão do significado do termo subtropical, segundo ele, tem sido a causa da dualidade de denominação do clima gaúcho.

A chuva é elemento de grande importância na classificação climática. No RS existe apreciável diferença quantitativa entre os valores normais das áreas menos chuvosas (1200 mm média anual) e das áreas mais chuvosas ( $2420 \mathrm{~mm}$ - média anual). Ainda, segundo Moreno 
(op. cit.), existe variação quantitativa, mas uniformidade na época das precipitações em todo o Estado.

Por estar localizado em latitudes subtropicais, o Rio Grande do Sul está constantemente sujeito às invasões de massas frias de origem polar, principalmente no inverno do Hemisfério Sul, sistemas que dão certa regularidade na dinâmica do processo de instabilidade do tempo gerando chuvas o ano todo. As chuvas não são periódicas, pois ocorre o ano todo.

No geral, Bagé possui um clima que tanto pode ser enquadrado no tipo subtropical ou temperado, com verões tépidos (com altas temperaturas durante o dia e temperaturas amenas à noite) e invernos relativamente frios, com geadas frequentes e queda de neve em ocasiões esporádicas (MORENO, 1961).

As precipitações costumam ser regularmente distribuídas durante 0 ano, mas estiagens esporádicas podem ocorrer. De acordo com a classificação do clima de Köppen, o clima do município é do tipo Cfa - Clima temperado chuvoso e quente; úmido em todas as estações, verão quente. (AYOADE, 2003).

A temperatura média anual é de $18^{\circ} \mathrm{C}$. O mês mais frio é julho, com temperatura média de $12^{\circ} \mathrm{C}$, enquanto janeiro, o mês mais quente, tem média de $24^{\circ} \mathrm{C}$. Quanto às precipitações, o volume médio anual é de $1.472 \mathrm{~mm}$. O mês considerado mais chuvoso é julho, com média de $142 \mathrm{~mm}$, e os meses menos chuvosos são abril e maio, com média de $104 \mathrm{~mm}$ (MORENO, 1961).

\section{FUNDAMENTAÇÃO TEÓRICA}

No Brasil, o trabalho realizado por Oliveira (1977) apresenta-se como marco na introdução aos estudos de percepção. Buscando a compreensão e influência dos processos cognitivos na percepção ambiental e paisagística, a autora afirma que os estudos em percepção ambiental relacionam-se com os esforços para entender como os homens estruturam mentalmente o mundo que os cerca.

Oliveira e Del Rio (1996) também contribuíram através da organização e publicação do livro intitulado Percepção Ambiental: a Experiência Brasileira, que tem por intuito abordar as questões do meio ambiente através de estudos aplicados da percepção, tendo como enfoque projetos pautados na percepção ambiental, na interpretação das realidades através dos estudos da percepção. 
As contribuições mais recentes foram publicadas por Pascoalino (2009) e Ribeiro (2012), em que a primeira desenvolveu trabalho sobre alterações climáticas e a percepção dos moradores de Rio Claro, SP, neste trabalho os estudos perceptivos se desenvolvem e estão voltados a cognição geográfica aliada às possíveis alterações climáticas, bem como de que forma elas são ou não são percebidas pela população do Município. O segundo aplicou o estudo da percepção de eventos pluviais extremos e estiagens a partir da análise da percepção ambiental e climática de moradores da zona rural e urbana na região das Missões, no Rio Grande do Sul (RIBEIRO, 2012). Com este estudo, comprovou-se a correlação estreita entre os resultados da pesquisa de percepção com os resultados da análise climática.

Seguindo essa linha de raciocínio, acredita-se que a análise da percepção por parte de populações de meios distintos (rural ou urbano) deva abordar os aspectos ligados às suas vivências e experiências em particular, principalmente quanto à gênese e evolução do tempo, que são percebidos de forma diferenciada, conforme as especificidades de cada meio. Assim, busca-se investigar questões da sabedoria popular e do conhecimento empírico e, também, das características tempo-sensitivas dessas populações, no caso de Bagé o público alvo elegido foi a população urbana.

Ao valorizar a experiência e vivência humana seja no meio rural ou urbano, segundo Capel (1973 p. 80) "toda investigação sobre percepção ambiental ou do espaço geográfico deve ter como ponto de partida concreto o meio real e seus habitantes dos quais devem ser obtidos os dados para a análise".

Segundo Sartori (2000), a interação do homem com seu local de vivência é a fonte básica para as pesquisas de percepção e a interação do homem com o ambiente foi desde os primórdios dos estudos fato a ser considerado.

Além da básica interação do homem com o meio ambiente, as calamidades decorrentes de extremos climáticos, neste contexto de análise de percepção do meio ambiente sempre merecem e ganham destaque como objetos de estudo. No Rio Grande do Sul as estiagens são exemplos já atestados por Ribeiro, (2012) que mobilizam a atenção da população por causarem uma série de impactos socioeconômicos e que muitas vezes chegam a ser calamitosos e são percebidos pela população mais antiga, não sendo novidade em território gaúcho.

No mundo todo, eventos de estiagem cujas repercussões produzem também a falta de alimentos são relatados desde os tempos mais remotos, inclusive, citados na Bíblia Cristã. 
Estudos realizados na Universidade de Nanquim revelaram que ao começar o ano 108 a.C, foram relatados na China e existência de períodos de fome, quase por um ano. No período de 1200 a 1600 segundo Willian Far, a Inglaterra sofreu épocas de fome numa média de uma a cada 15 anos. As pessoas eram obrigadas a comer gatos, ratos, raízes de plantas, cães e carne humana. O mesmo aconteceu em muitos outros Países (SAMPAIO, 2010).

Só após a Revolução Industrial, com o melhoramento dos meios de comunicação e de armazenamento de alimentos a situação melhorou. Iniciou-se tal melhora no fim do século XVIII. Não quer dizer que ainda não exista fome, não por fatores ligados ao transporte e produção, mas por outros fatores, como as climáticas e principalmente a estiagem.

Mas ainda neste Século XXI, como é possível reter água no solo em zonas secas? Uma das soluções seria a utilização de palha adquirida com a roçada, que produzirá os mesmos resultados que o "alqueive", sistema esse que tem a finalidade de armazenar água, destruir inços, favorecer a decomposição da matéria orgânica, produção e incorporação de nitrogênio no solo possibilitando altos rendimentos de colheitas e pastagens (POSTEL, 1993). A água disponível no território brasileiro é suficiente para as necessidades do País, apesar da degradação. Seria necessária, então, mais consciência por parte da população no uso da água e, por parte do governo, um maior cuidado com a questão do saneamento e abastecimento.

Por exemplo, $90 \%$ das atividades modernas poderiam ser realizadas com água de reuso. Além de diminuir a pressão sobre a demanda, o custo dessa água é pelo menos $50 \%$ menor do que o preço da água fornecida pelas companhias de saneamento, pois não precisa passar por tratamento (POSTEL, 1993).

Apesar de parte desta água ser inadequada para o consumo humano, poderia ser usada, entre outras atividades, nas indústrias, na lavagem de áreas públicas e nas descargas sanitárias de condomínios. Além disso, as novas construções, casas, prédios, complexos industriais, poderiam incorporar sistemas de aproveitamento da água da chuva, para os usos gerais que não o consumo humano. Sabe-se que tais procedimentos já vêm sendo adaptados em diversos lugares, mas a regularização ou exigência em forma de lei ainda caminha a passos muito lentos.

A água disponível para consumo humano representa um pequeno percentual e concentra-se em alguns países, como Brasil, Rússia, China e Canadá. Muitas regiões do mundo sofrem com a falta de água doce. Mesmo no interior desses países citados, apesar de haver disponibilidade de água, há lugares que sofrem com a escassez, como é o caso de áreas 
semiáridas do nordeste brasileiro, em períodos específicos, assim como em cidades do Rio Grande do Sul. Esse problema também se manifesta em outras partes do Brasil, em virtude de falhas de abastecimento, da intensa poluição e também da cultura do desperdício (POSTEL, 1993).

A costa atlântica brasileira, por possuir um elevado índice pluviométrico, tem o seu estresse hídrico minimizado. Mesmo assim, a grande concentração populacional e industrial do Centro-Sul, é motivo de preocupação.

O aumento da população mundial, da urbanização, da irrigação da produção industrial e da atividade econômica em geral é uma ameaça do abastecimento de água. As atividades domésticas, como banhos demorados e lavagem de calçadas, e os vazamentos na rede de fornecimento de água tratada também contribuem para o risco de escassez de água potável (POSTEL, 1993).

Nas cidades, ou áreas urbanas, onde há concentração populacional, a água é buscada cada vez mais longe, o que encarece o abastecimento, além de não ser disponibilizada para todos. É grande o número de pessoas que não têm acesso à água tratada, o que provoca muitas doenças. Portanto, torna-se necessária a contribuição dos governos e da sociedade na busca de soluções para a crise da água. Reduzir o consumo e tratar a água já utilizada, tornando-a novamente potável, poderia ser algumas das soluções.

Ainda que muitos discursos afirmem que a água vai acabar no futuro, é importante destacar que a quantidade desse líquido na Terra é praticamente a mesma há centenas de anos, alterando-se somente sua distribuição e seu estado físico (POSTEL, 1993).

Não faltam sinais de escassez de água doce. Os níveis dos lençóis freáticos baixam constantemente, muitos lagos encolhem e pântanos secam. Na agricultura, na indústria e na vida doméstica, as necessidades de água não param de aumentar paralelamente ao crescimento demográfico e ao aumento nos padrões de vida, que multiplicam o uso da água. Muitos acreditam erroneamente, que o consumo de água é proporcional ao número de habitantes de cada lugar no mundo.

Nos últimos 20 anos, tem havido um significativo aumento do uso da água para a produção de alimentos e de energia. Isso vem ocorrendo basicamente para satisfazer a demanda de uma produção e uma população crescente, e para melhorar o bem estar humano, uma tendência observada na sociedade do consumo. Entretanto, a maneira como a água vem sendo utilizada tem provocado significativos efeitos negativos, requerendo uma atenção urgente por parte de todos para que seja garantida a sustentabilidade. As soluções, porém 
podem ser locais, mesmo que as convenções e os acordos sejam estabelecidos em nível internacional (POSTEL, 1993).

\section{MATERIAIS E MÉTODOS}

As formas de investigação da percepção das pessoas que tenham vivenciado determinados fenômenos naturais não são fáceis de encontrar nos estudos de diversos autores, no entanto são aplicadas, obviamente, à realidade pessoal de cada área de estudo e objetivos de trabalho.

Em função disto, neste estudo, classificado como exploratório e explicativo, com pesquisa bibliográfica e documental, a fim de se conhecer os fundamentos e as contribuições sobre os problemas ambientais enfrentados pela cidade de Bagé (RS) em decorrência das estiagens que castigam o município, a pesquisa baseou-se na metodologia utilizada por Wollmann; Sartori (2010) e por Ribeiro (2012), que consiste na aplicação de questionário de perguntas abertas e fechadas para a população de áreas atingidas por extremos climáticos.

O ANEXO 01 apresenta o Questionário aplicado a essa população Bageense. Antes de iniciar a questão 01, foi-Ihes perguntado também o sexo e escolaridade.

Foi utilizado o aplicativo MS EXCEL 2010, utilizado para a análise estatística e construção de tabelas e gráficos.

Pretendeu-se sempre entrevistar pessoas com faixa etária acima de 18 anos de idade. Foram analisadas as variáveis: sexo, período de estiagem, motivo pelo qual falta água, conhecimentos dos moradores sobre projetos, em relação as medidas tomada e por último, qual a maneira ou conscientização de uso da água. Feito isso, foram elaborados tabelas, gráficos com os respectivos percentuais de ocorrências de cada questão do questionário.

\section{RESULTADOS E DISCUSSÕES}

Foi entrevistado um total de 39 pessoas na área urbana de Bagé, RS. Quanto ao grau de instrução, $55 \%$ do total entrevistados têm o nível superior e $45 \%$ tem o ensino médio. A Figura 03 apresenta o total de entrevistados na pesquisa, dos quais $70 \%$ do sexo feminino e $30 \%$ do sexo masculino. 


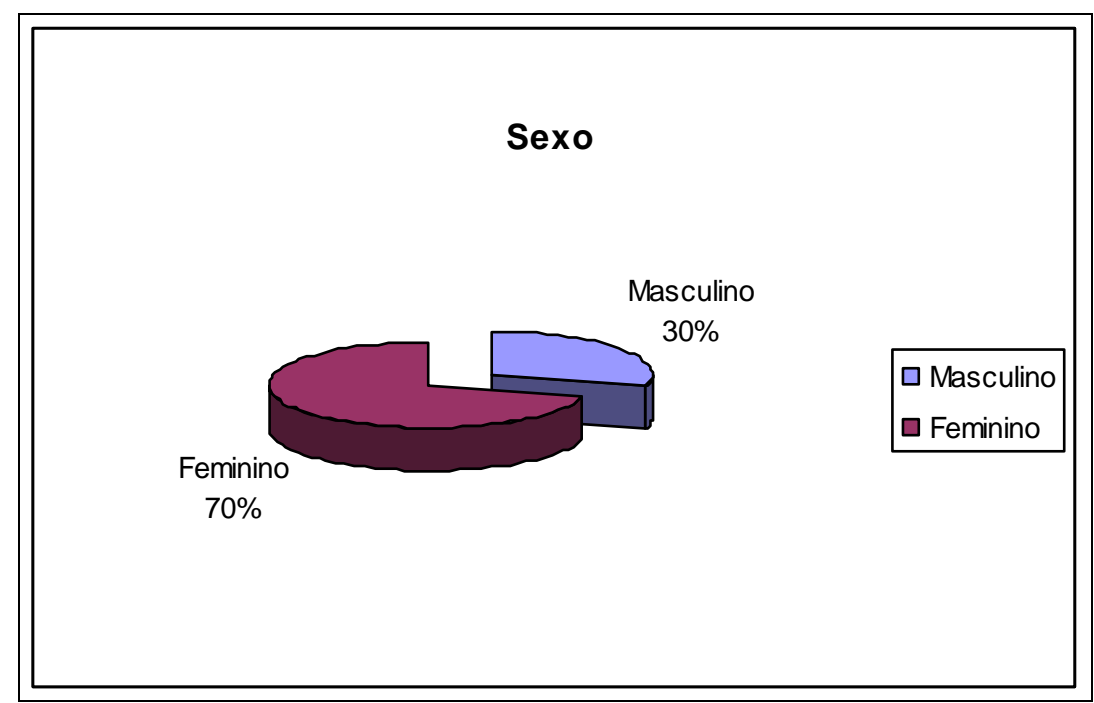

Figura 03: Percentual do Gênero das pessoas entrevistadas. Elaborado pelo autor.

Com relação ao período de estiagem, há quanto tempo vem acontecendo o fenômeno, na percepção dos entrevistados, 31\% do total responderam que já acontece a estiagem há até 10 anos; $41 \%$ dos entrevistados disseram que esse fenômeno acontece num período de 10 a 25 anos. 5\% confirmaram que isso ocorre num período de 25 a 50 anos. $13 \%$ confirmam que isso vem ocorrendo a mais de 50 anos; e 10\% do total geral não declararam. Portanto, percebe-se que no período de 10 a 25 anos, na percepção da população urbana de Bagé, há uma maior frequência de ocorrência de estiagem no município (Figura 04).

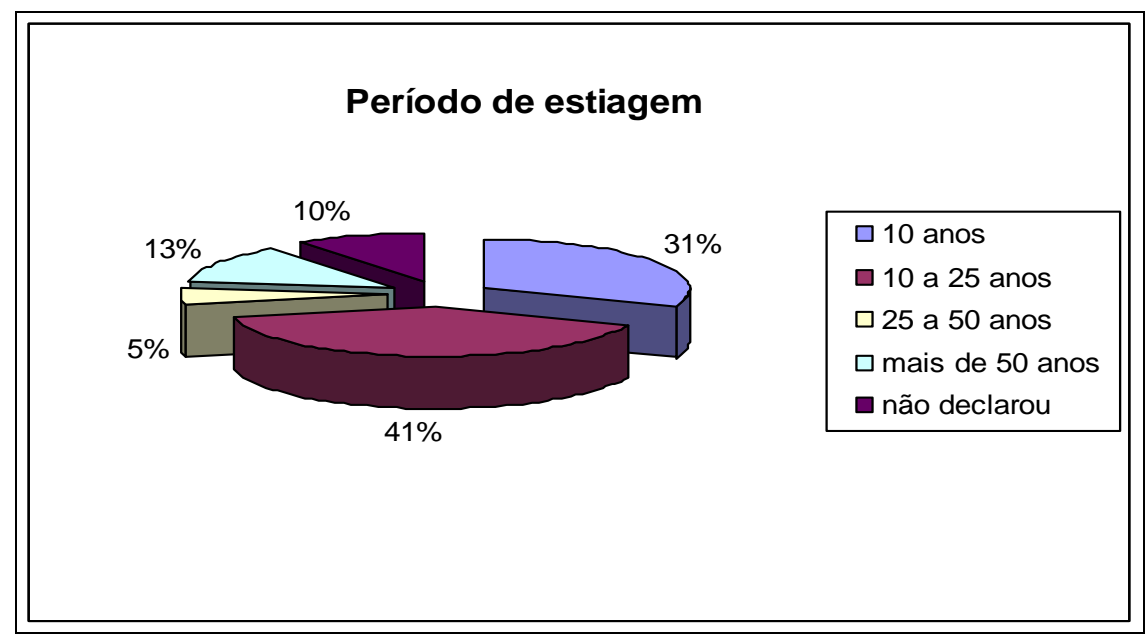

Figura 04: Percepção da ocorrência de estiagem no município. Elaborado pelo autor.

Com relação à falta de água como mostra a Tabela 01, os entrevistados argumentam que as principais prováveis causas são: $48 \%$ supõem que as barragens são antigas e não comportam 
o crescimento do consumo; $3 \%$ concluem que o município não planejou/acompanhou 0 crescimento natural da população; e 49\% entendem que são os dois fatores.

Quanto ao conhecimento da população bageense em relação a projetos que estão sendo feitos e analisados pelos governantes, sendo eles, Prefeitura Municipal e Governo do Estado, Departamento de Água e Esgotos de Bagé (DAEB), entre outros órgãos, no que se refere ao conhecimento, ou informação da população sobre os órgãos que trabalham para amenizar a problemática da estiagem em Bagé, $92 \%$ dos pesquisados responderam que sim, tem conhecimento sobre a atuação de algum órgão; 8\% não têm nenhuma informação. Isto é, não sabem. Tal resultado é bem visível conforme mostra a Figura 05.

Tabela 01 - A tabela refere-se ao provável motivo da falta de água.

\begin{tabular}{ccc}
\hline Falta de água & Total & (\%) Percentual \\
\hline As barragens são antigas e não comportam o crescimento do consumo & 19 & $48 \%$ \\
\hline O município não acompanhou o crescimento natural da população & 01 & $3 \%$ \\
\hline Responderam as duas perguntas & 19 & $49 \%$ \\
\hline Total & $\mathbf{3 9}$ & $\mathbf{1 0 0 \%}$ \\
\hline
\end{tabular}

Elaborado pelo autor.

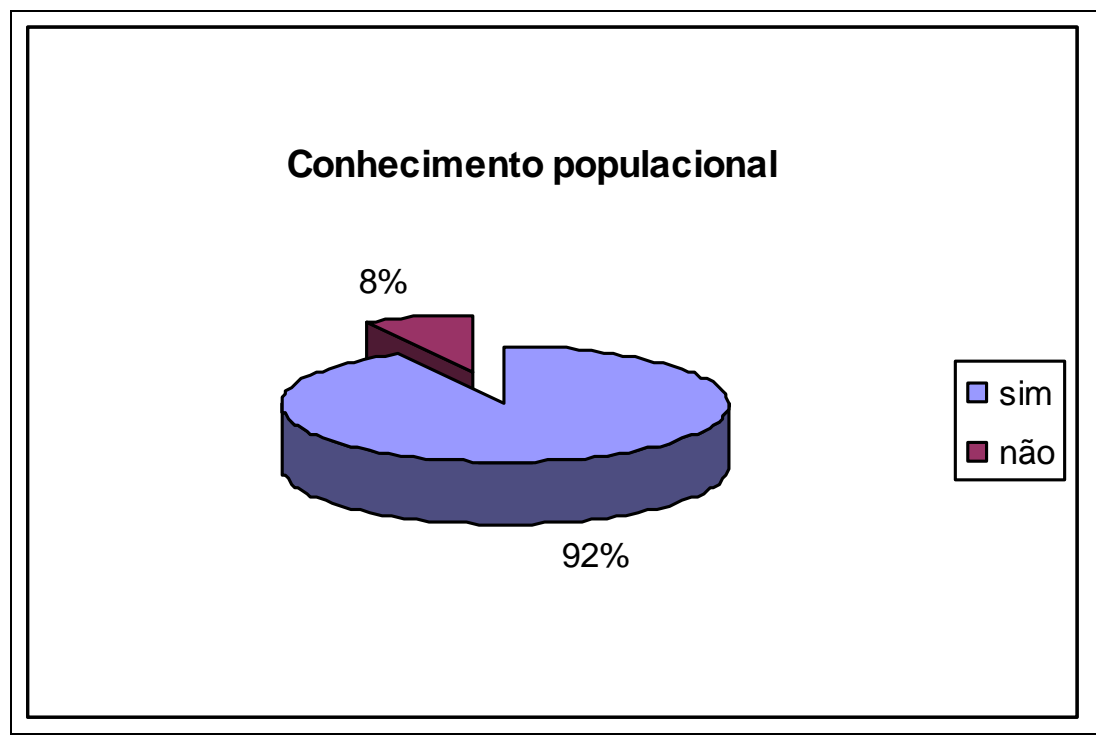

Figura 05: Conhecimento da população em relação a projetos dos poderes públicos referente à possível solução das estiagens.

Elaborado pelo autor.

A credibilidade dos projetos de construção de barragens de abastecimento para amenização dos problemas de falta de água em épocas de estiagem prolongadas executados e não executados no município de Bagé nas últimas décadas, na visão da população, 34\% responderam que acreditam em bons projetos; $66 \%$ não acreditam que tenham algum projeto para sanar o problema de estiagem, pois acham é questão política e falta de interesse dos responsáveis, o resultado está expresso na Figura 06. 


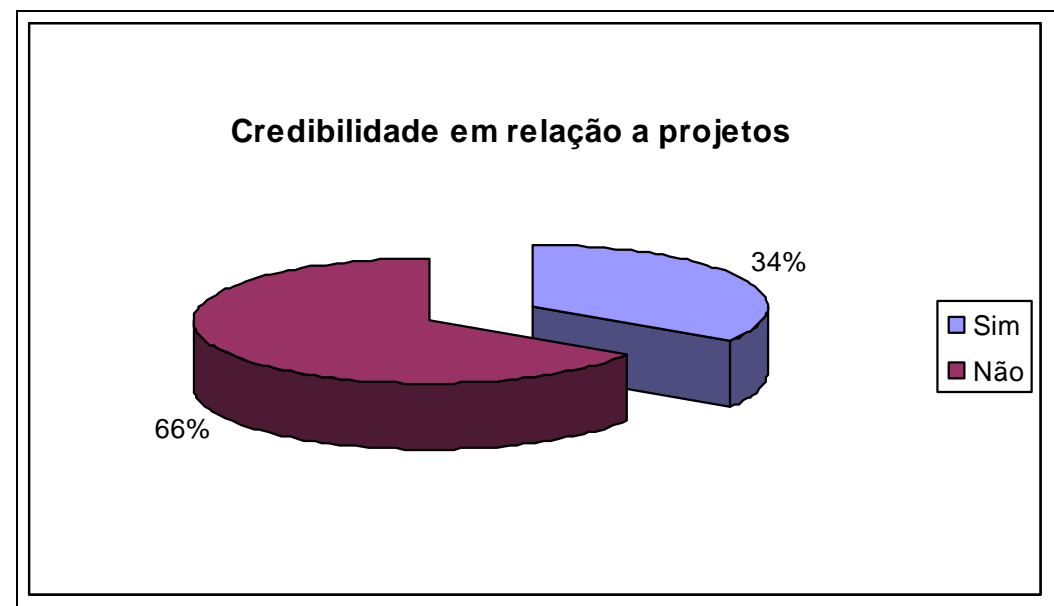

Figura 06: Credibilidade da população em relação aos projetos executados e não executados no município de Bagé pelos poderes públicos.

Elaborado pelo autor.

Em relação às soluções mais plausíveis para a problemática das estiagens, $71 \%$ dos entrevistados sugerem a construção de novas barragens; $8 \%$ de poços artesianos e $21 \%$ sugeriram várias outras ideias: como mais tecnologias, mais recursos financeiros, maior iniciativa política (Figura 07).

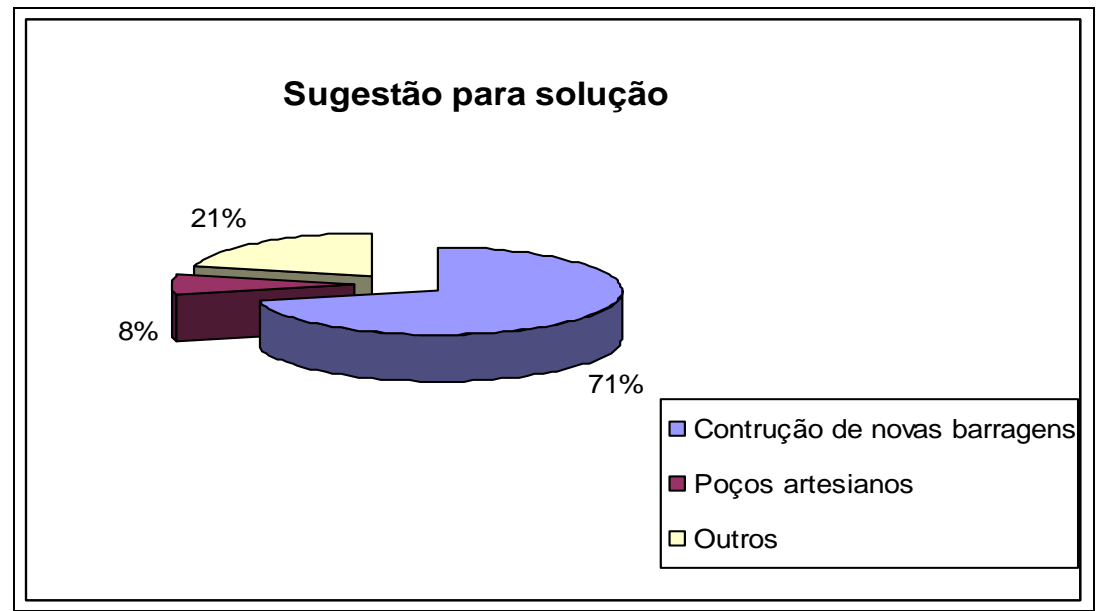

Figura 07: Sugestões apresentadas pela população para a solução do problema de estiagem no Município de Bagé, RS.

Elaborado pelo autor.

No que se refere à conscientização da população conforme a Figura 08, o uso adequado da água, salientado por 77\% dos entrevistados, é entendido que se torna necessário evitar todo e qualquer tipo de desperdício; $15 \%$ referem-se à diminuição, e/ou proibição do uso da água para a lavagem de calçadas e carro já seria suficiente para reduzir o problema de falta de água em períodos de estiagem em Bagé; e, finalmente, $8 \%$ dos entrevistados colocam que evitar o desperdício doméstico é o suficiente. 


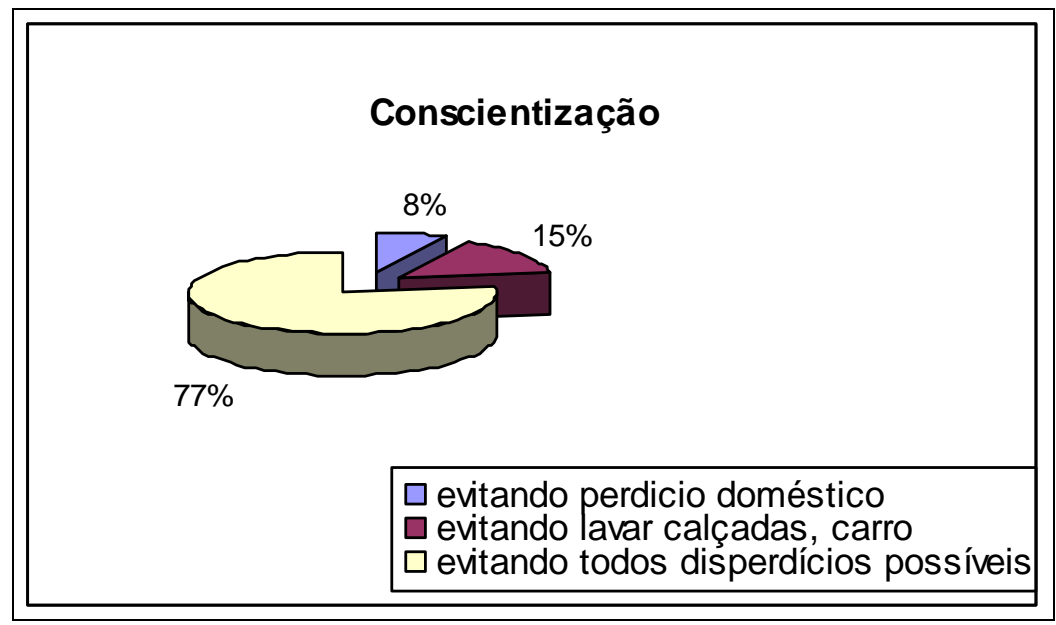

Figura 08: Medidas de conscientização da população em relação ao uso da água - percepção de possíveis soluções.

Elaborado pelo autor.

Nesse sentido, de acordo com os resultados obtidos junto à população urbana de Bagé, RS, o problema da falta de água provocado pelas estiagens poderia ser resolvido se:

$\checkmark$ A população consciente do sério problema, eleger representantes tanto para o legislativo (vereadores) e Executivo (prefeito) cidadãos comprometidos com a causa.

$\checkmark$ O Município apresenta projetos viáveis ao Governo Estadual e Federal respectivamente que beneficie a comunidade bageense com recursos para a execução de barragens de funcionamento a breve e médio prazo como solução definitiva.

$\checkmark$ O Governo Municipal continuar com o programa de distribuição de caixas d'água (reservatórios residenciais) atingindo o máximo possível das famílias de baixa renda, tanto na zona urbana como na zona rural.

$\checkmark$ O Governo Municipal deverá viabilizar a realização de Seminários, Simpósios, Encontros entre outros, para esclarecer e conscientizar tendo como foco famílias de alunos da Rede Escolar Municipal que em sua maioria localizam-se em bairros afastados do centro da cidade.

$\checkmark$ Colocação de hidrômetros como medida educativa e não punitiva economicamente (aumento do valor da conta de água, mesmo não oferecendo o produto). 


\section{CONSIDERAÇÕES FINAIS}

A ocorrência de estiagens no município de Bagé, Rio grande do Sul, foi investigada nesse trabalho através de pesquisa de amostragem da população bageense em seus respectivos resultados, onde foi realizado um trabalho investigativo a respeito da situação da estiagem em Bagé e suas consequências para a população em seu cotidiano.

Observou-se que a população percebe a ocorrência de fenômenos de estiagem há pelos menos 25 anos, ou seja, tal situação climática leva à ocorrência de falta de água, pelo menos no verão, na zona urbana de Bagé, há pelo menos duas décadas, bem como observou-se o descaso com o uso da água, não ocorrendo racionamento nem medidas pessoais de racionamento desse recurso em situações de escassez.

Após o término do levantamento, conclui-se, que esse tipo de pesquisa poderá servir de apoio para os profissionais da prefeitura, a comunidade, governantes e o desenvolvimento de práticas cabíveis nas barragens que abastecem o município num todo.

Constatou-se que os moradores reconhecem a execução de políticas públicas e que estas estão sendo implantadas através de verbas federais, tais como a grande construção da Barragem da Arvorezinha obra esta que tem como promessa resolver definitivamente o problema da estiagem em Bagé e Região.

\section{REFERÊNCIAS BIBLIOGRÁFICAS}

AYOADE, J. O. Introdução à climatologia para os trópicos. Rio de Janeiro: Bertrand Brasil, 2003.

BORGHETTI, J. R; BORGHETTI, N. R. B.; ROSA, F.; ERNANI, F. Aquífero Guarani: A verdadeira integração dos Países do MERCOSUL. Curitiba: CRA. 2004. 80 p.

CAPEL, H. Percepción Del médio y comportamiento geográfico. Revista de geografia, VII (1y2) p. 58-150, Universidade de Barcelona, 1973.

CARVALHO, O. A economia política do Nordeste (seca, irrigação e desenvolvimento). Rio de Janeiro, Brasília: Campus. ABID. 1988.

CHOMENKO, Luiza. Secas versus Enchentes. Porto Alegre: Fundação Zoobotânica do RS, 2008. 
COLVILLE, P. G. Condicionantes climáticos à desertificação. Talca: Facultad de Ciências Agrárias, Universidad de Talca, Chile, 1987.

CONTI, J. B. O conceito de desertificação. Revista Climatologia e Estudos da Paisagem. Rio Claro: UNESP. v. 3, n. 2, p. 39-53. 2008.

DEL RIO, V; OLIVEIRA, L. (Org.) Percepção ambiental: a experiência brasileira. São Paulo: Estúdio Nobel, Universidade Federal de São Carlos, 1996.

GOMES, M. A. F. A água nossa de cada dia. Bagé: Secretaria Municipal De Meio Ambiente, 2012.

INSTITUTO BRASILEIRO DE GEOGRAFIA E ESTATÍSTICA - IBGE. Censo 2010 $<\underline{w w w . c e n s o 2010 . i b g e . g o v . b r / p r i m e i r o s d a d o s d i v u l g a d o s / i n d e x . p h p ? u f=43}>$ Acesso em $21 / 08 / 2012$.

LE MONDE DIPLOMATIQUE - BRASIL. Atlas do meio Ambiente. Curitiba: Instituto Pólis, s/d.

MORENO, J. A. Clima do Rio Grande do Sul. Porto Alegre: Secretaria da Agricultura, 1961.

OLIVEIRA, F. L. A percepção climática no município de Campinas-SP. 2005. 84f. Dissertação (Mestrado em Geografia) - Instituto de Geociências, Universidade Estadual de Campinas, Campinas, 2005.

OLIVEIRA, L. M. Estudo metodológico e cognitivo do mapa. Tese de Livre-Docência, Departamento de Geografia e Planejamento, Instituto de Geociências e Ciências Exatas, UNESP, Rio Claro, 1971.

L. M. Contribuição dos estudos cognitivos à percepção geográfica. Geografia. 2 (3). p. 61-72. Rio Claro1977.

PASCOALINO, A. Alterações climáticas e a percepção dos munícipes de Rio Claro - SP. 2009. Dissertação Mestrado. Programa de Pós-Graduação em Geografia, Organização do Espaço. Universidade Estadual Paulista. Rio Claro, 2009

POSTEL, S. Uma escassez anunciada. Revista O Correio, Rio de Janeiro: UNESCO, Jul. 1993.

RIBEIRO, A. de. A. Eventos Pluviais Extremos e Estiagens na Região das Missões, RS: a percepção dos moradores do município de Santo Antônio das Missões. Dissertação 
(Mestrado em Geografia; Organização do Espaço) Instituto de Geociências e Ciências Exatas

- Universidade Estadual Paulista. Rio Claro, SP, 2012.

RUOSO, D. O clima de Santa Cruz do Sul - RS e a percepção climática da população urbana. 2007. Dissertação (Mestrado em Geografia) - Centro de Ciências Naturais e Exatas, Universidade Federal de Santa Maria, Santa Maria, 2007.

SAMPAIO, F. S.; SUCENA, I. S. Ser Protagonista. São Paulo: Edições SM, 2010. 113 p.

SILVEIRA, R. D.; SARTORI, M. G. B.; SILVA, R. R.; ROSA, J. L. A estiagem do verão de 2005 no RS: causas e impactos socioeconômicos na microrregião geográfica de Santa Maria. In: SIMPÓSIO BRASILEIRO DE CLIMATOLOGIA GEOGRÁFICA, 7., 2006, Rondonópolis. Anais... Rondonópolis: UFMT, 2006. 1 CDROM.

SARTORI, M. G. B. Clima e Percepção. 2000. V. 1 e 2. Tese (Doutorado em Geografia Física) Faculdade de Filosofia, Letras e Ciências Humanas da Universidade de São Paulo, São Paulo, 2000.

TEIXEIRA, W. et. al. Decifrando a Terra. São Paulo: Companhia Editora Nacional, 2. ed. 2009.

WOLLMANN, C. A.; SARTORI, M. G. B. A Percepção Ambiental e Climática da População de São Sebastião do Caí como forma de Previsão de Enchentes na Bacia Hidrográfica do Rio Caí Rio Grande do Sul. Revista brasileira de climatologia, v. 06, p. 107-134, 2010.

Artigo recebido em 29/08/2013.

Artigo aceito em 16/09/2013. 


\section{ANEXO 01}

Plena (Ead)

Trabalho de Pesquisa da acadêmica Ana Rosa Pacheco Brondani

$\frac{\text { I - Identificação: }}{N^{2}:-2 a t}$

No:

Sexo:（）M ( ) $F$

Grau de Instrução:-

II - Informações para a pesquisa:

1. Desde quando você se lembra que ocorrem problemas de falta água em Bagé?

( ) Aproximadamente 10 anos

( ) Entre 10 e 25 anos

( ) entre 25 e 50 anos

( ) Mais de 50 anos

2. Você saberia por qual(ais) motivo(s) ocorre falta água em Bagé?

( ) O Município não acompanhou o crescimento natural da população.

( ) As barragens são antigas e não comportam o crescente consumo.

( ) Todas as anteriores

3. Você tem conhecimento se as autoridades de Bagé, ou do Governo Estadual, estão realizando algum projeto sobre a estiagem?
( ) sim
( ) não.

4. Você acredita que as medidas que estão sendo tomadas pelo Governo Municipal e/ou Estadual estão sendo suficientes para resolver o problema?

( ) $\operatorname{sim}$
( ) não

5. Para você, quais seriam as medidas corretas para tentar solucionar definitivamente 0 problema da estiagem em Bagé?

6. Quais as medidas que cada indivíduo deve fazer para tentar solucionar o problema?

( ) Evitando desperdício doméstico ( louças e banho).

( ) Evitando lavagem de calçadas, carros.

( ) Todas as formas possíveis. 